and gives references to any matter affecting their design, construction, economics and use. It includes the findings of scientific research, of such systematic but less-precise forms of investigation as surveys, and of field trials and similar developmental phases of new techniques. It includes information from any country where conditions are relevant to Great Britain. Abstracts of the original material and a review summarizing the main conclusions are provided. The present bibliography covers the period January 1, 1945, to April 30, 1958. The Council intends to keep it up to date by publishing supplementary bibliographies from time to time. Buildings for the Drying and Storage of Grain (3s., postage $3 d$.) is obtainable from the Agricultural Research Council, Cunard Building, 15 Regent Street, London, S.W.1.

\section{Public Health as a World Problem}

THE fourth report from the World Health Organization's Expert Committee on Public Health Administration, of which Sir John Charles is chairman, is entitled The Planning of Public Health Services (Technical Report Series, No. 215. Pp. 48. Geneva: World Health Organization; London: H.M.S.O., 1961. 2 Swiss francs; $3 s .6 d . ; 0.60$ dollars). It reviews broadly the experience in this field of Ceylon, India, Czechoslovakia, the U.S.S.R., the United Arab Republic and the United Kingdom, before considering in detail the general principles of planning such services in countries at varying stages of development and with different social and economic systems, to which any planning must be related. Stress is laid on the use of surveys to secure the information on which planning must be based, the importance of securing full co-ordination and collaboration from the medical and other professions concerned and the interest and understanding of the general public. The determination of priorities and the choice of long-term targets are also necessary, and since planning is a continuous process arrangements should be made for continuous review and assessment, so that the health programme is kept constantly in line with changing conditions; and in this connexion the value of operational research is emphasized. It is no longer satisfactory to plan health services on an empirical basis, and further research in public health service is needed to provide indicators for assessing on a more scientific basis the level of public health, the efficiency of health services, standards, and the economics of disease and disability and their reduction.

\section{National Foundation for Scientific Research, Belgium}

The thirty-third annual report of the Belgian National Foundation for Scientific Research, covering the year 1959-60, comprises chiefly alphabetical lists of recipients of grants and of their publications during the year, in which grants totalling 39 million francs were voted (Fonds National de la Recherche Scientifique. Trente-troisième Rapport Annuel, 1959-60. Pp. 284. Bruxelles: Fonds National de la Recherche Scientifique, 1961). Of this total, 382,500 francs was to the Unive sity of Ghent, 240,000 frencs to the University of Liège, 730,000 francs to the University of Brussels and 850,000 francs to the University of Louvain. Special grants noted in the report include $1,000,000$ francs to the Committee for the Study and Exploitation of Electronic (alculators; 1,875,000 francs for research programmes concerned with the technique of regulation (chemical processes and stochastic phenomena) of the transmission of heat, automobile suspension and the mechanics of flight; 300,000 francs for studies of the effect of $P, Q, R, S, S T$ and $T$ waves of the vectorial electrocardiogram of man, the dog and the rabbit; 2,175,000 franes for a study of dynamic and static deformations, stresses, vibrations and temperatures in construction; 500,000 francs for studies to determine the structure of natural products (sesquiterpenes, steroids, triterpenes and alkaloids); and 300,000 francs for a study of the diffusion of atoms and free radicals in the solid phase at $4^{\circ} \mathrm{K}$. as a function of their masses. There is also a note on research during the year at the Jungfraujoch scientific station.

\section{Teachers and Health Education}

Health education is not always recognized as a discipline of its own and given its appropriate place in the training of teachers. A new report (Joint WHO/Unesco Expert Committee on Teacher Preparation for Health Education. World Health Org. Tech. Rep. Ser., 1960. No. 193. Pp. 19. 1s. 9d. Published also in French and Spanish) provides a flexible framework of guiding principles for such training, which should take place not only through courses of instruction but also through the teacher's actual mode of life in his training institution, his contact with student health services, and his experiences when practising teaching. Health education in schools should be based on the health needs and interests of the children, the teacher having many opportunities for imparting it both directly and by the part he can play in the school health services and in planning for a healthy school. To enable him to make the most of his opportunities, he must have some knowledge of growth and development, personal and community health, school health practice, and methods of health education. The report discusses these subjects, the future teacher's life as a student in relation to his opportunities for health work and to student health services, practice teaching, and the education he acquires as a fully-fledged teacher. Other sections deal with planning of training for teachers in health education, the desirability of one person in each training institution being responsible for co-ordination of courses and activities in health education, and possible future national and international developments, studies and research in the subject.

\section{Hospital Efficiency Studies}

THE Ministry of Health has issued recently, to hospital authorities, a second set of Abstracts of Efficiency in the Hospital Service. The first set, comprising seven investigations, was published in April. The aim of the series is to enable all hospitals to profit from simplification, improvements and moneysaving ideas which have been found practicable in the hospital field and to reduce the risk of related measurements and tests being unnecessarily repeated. All the hospital authorities have been asked to contribute to the series by supplying brief factual details from studies they have undertaken. The second set is made up of six studies. These cover: maintenance of grounds and gardens; document copying; medical stenographers' department; medical records (including mobile steel-shelving and addressing machine systems); and, finally, the collection of swill from hospital wards. 